The Emotional Mind 



\title{
The Emotional Mind THE AFFECTIVE ROOTS OF CULTURE AND COGNITION
}

Stephen T. Asma

Rami Gabriel

\author{
III \\ II \\ Harvard University Press \\ Cambridge, Massachusetts - London, England \\ 2019
}


Copyright (C) 2019 by the President and Fellows of Harvard College All rights reserved

Printed in the United States of America

\section{First printing}

Cover design: Tim Jones

Cover art: Phrenology head lying sideways $(\mathcal{D}$ David Muir / Getty Images

$$
\begin{aligned}
& 9780674238923 \text { (EPUB) } \\
& 9780674238930 \text { (MOBI) } \\
& 9780674238916 \text { (PDF) }
\end{aligned}
$$

The Library of Congress has cataloged the printed edition as follows:

Names: Asma, Stephen T., author. | Gabriel, Rami, author.

Title: The emotional mind : the affective roots of culture and cognition / Stephen T. Asma, Rami Gabriel.

Description: Cambridge, Massachusetts : Harvard University Press, 2019. I Includes bibliographical references and index.

Identifiers: LCCN 2018046433 | ISBN 9780674980556 (hardcover : alk. paper)

Subjects: LCSH: Emotions. | Human evolution. | Emotions and cognition. | Social evolution. | Evolutionary psychology.

Classification: LCC QP401 .A76 2019 | DDC 612.8/232-dc23 LC record available at https://lccn.loc.gov/2018046433 
For Tom Greif and Jaak Panksepp 
